\title{
Ergonomics and Quality - An Ergonomic Quality Assessment Model for the Work Sta- tion Using the Parameters Established under the Brazilian Regulations on Ergonomics (NR-17)
}

\author{
Carlos Maurício Duque dos Santos and Pedro Luiz Oliveira Costa Neto \\ Paulista University - UNIP, Brazil \\ Email:mauricioduque@uol.com.br
}

\begin{abstract}
This study aims to present and assess a management model for implementing ergonomic improvements in the quality of working conditions in production processes in order to meet the requirements of Regulation Standard NR-17 (Brazilian Health and Safety Labor Regulations), which is an integral part of the Brazilian Labor Legislation. The object was to create a Company Ergonomics Management Model. The management model was implemented in two companies on their manufacturing production lines producing different products and demonstrating satisfactory results.
\end{abstract}

Keywords: Ergonomics, Quality, Management Model

\section{Introduction}

In Brazil, concern for the improvement in product quality and quality of life regarding production systems is constantly and continually on the increase in the light of international certification systems and the requirements of Brazilian Legislation, which have all been the subject for research in various learning areas, including the areas of production administration, production engineering and occupational health and safety.

This study presents a tool for improving the ergonomic quality in working conditions for production processes. The model was developed and as a reference, used the concept of ergonomic suitability for the Work Station in order to meet the requirements of Regulation NR-17 for Ergonomics (a Brazilian standard which all companies must follow), the concept of Participatory Ergonomics (Noro \& Imada 1991 apud lida, 2005) and, for the improvement of ergonomic quality of working conditions in production processes, the concepts of OHSAS 18.001:2007 were also used.

\section{Objectives}

As the main objective, the research in question had to create an effective, simple and objective tool, in order to meet the legislation and consequently improve ergonomic quality for working conditions in the production process.

As a secondary objective for the research we have the training of the company internal work force to diagnose and implement ergonomic improvements at the work stations and in the general working conditions

\section{Explanations}

a. To meet the legislative requirements relative to workers health and safety (Regulatory Standards relative to Occupational Health and Safety contained in Chapter V, Vol II of the CLT - Consolidation of La- 
bor Laws -, especially regulation NR-17 on Ergonomics) which addresses ergonomic improvements in the Work Station and in production processes, as well as meeting the requirements of OHSAS 18.001:2007, international standards set by ISO - International Standardization Organization.

b. To meet the union and work stations workers relative to operational quality, operational needs and facilities in respect to comfort and safety, in order to minimize the risk from occupational diseases and accidents.

\section{Bibliographic References}

In order to promote a more ample and broader vision, holistically relevant to the object of this study, it was necessary to briefly study the concepts, definitions and approaches of some areas of interrelated knowledge which complement each other when in regards to implementing improvements for ergonomic quality in the work station and in production processes, which are: Quality and Ergonomics.

\subsection{Quality}

The term quality; a noun (feminine), meaning to distinguish attributes, property or the condition of objects, people or things, has gained a special relevance upon being viewed as having economic significance and consequently, a competitive differential. To this end, quality is tangible, measurable and provides added value.

From a market perspective, quality is continuous and comprehensive whole. It is comprehensive through the extrapolation of concrete and determining aspects of the production or service relative to conformity, for the incorporation of subjectivity of opinion, for satisfaction, personal taste and client/consumer personality

Acording [6] "Quality is the sum of all the characteristics and properties of goods and services offered which meet the reasonable demands of the clients, together with a set of situations involved for obtaining and using these products which promotes a healthy and authentically humane existence for all those involved".

For [3], "ergonomic quality is that which ensures a good interaction of the user within the work station. Which includes: ease of handling, anthropometric adaptation, providing clear information, and ease of use or navigation, compatibility of movement and other comfort and safety items".

On the other hand, the importance of quality and also productivity from work processes for company competitiveness must be considered. By competitiveness for a company, this may be construed as the capacity to "maintain or increase a slice of the market for their products or services, enabling them to confront the actions of their competitors", [6] page 87 .

\subsection{Ergonomics}

The International Ergonomics Association I.E.A., approved a definition in August, 2000, contained in [5], conceptualizing ergonomics and its specialties, as follows, "Ergonomics is a scientific discipline related to the understanding of interactions between humans and other elements or systems and for its theoretical, principles, project data and methods applications to projects in order to optimize human well being and overall systems performance".

The three areas of Ergonomic specialization according to the IEA, applied to all aspects of human activity, as follows: the physical ergonomics, the cognitive ergonomics and the organizational ergonomics, also mentioning that these three fields of Ergonomics application are not mutually excluding and are constantly evolving [5].

As stated by [4], page 19, Generally speaking, ergonomics can be understood as a discipline which aims to transform work in its different dimensions, adapting it to the human's characteristics and limits. In this sense, Ergonomics surpasses the Taylorism concept of 'Homo Economicus' - The Economic Human -, demonstrating the limitations of the reductionist point of view in which only the physical work is considered, revealing the complexity of work and the multiplicity of factors which it is composed of ".

According to [2] "The vast majority of authors who discuss ergonomic action cite the importance of validation as a step or means towards assessment, verification and/or restitution of knowledge along with the workers at the intervention site".

As advocated by [1], the search for science in Ergonomics should commence form the practical point 
of view. If the priority of Ergonomics is the production of ergonomic production; its effective use must be in the assessment of the results. That is, to assess the effective transformation of the ergonomic action.

With the conceptual and theoretical evidence explained by [1] and [2], the need for a worker and company ergonomic contributions assessment system becomes ever clearer. The authors' understanding of the work, the assessment of ergonomic action (in the Work Station and the working conditions), is only possible with a Company Ergonomics Management System and if possible, this system should be participative (such as, with the effective contribution of the company workforce, especially relative to their real needs and in the validation of any ergonomic action taken).

\subsection{Ergodesign}

The term ergodesign is being used to define and/or conceptualize product designs, Work Stations and production processes which apply the knowledge of Ergonomics in the conception of the design of the product, the design of the production process and the work organization (Organizational Design and Management - ODAM). In this study we use the concept of ergodesign for the Company Ergonomic Management design process, which will be presented in our case studies

\section{Presentation of Assessment Model}

The model was conceived using the concept of "participatory management". Participatory Management in Ergonomics is understood to be a set of principles and processes which enable the participation of the workers/collaborators in various organizational choices relative to improving work conditions and Work Station, aiming at comfort, security and efficient performance. The participatory ergonomics management model covers the provisions in NR-17 on Ergonomics and also meets the requirements of OHSAS 18.001, which advocates the improvement of work conditions in production processes.

The model for improvement of ergonomic quality of working conditions in production processes is a participatory management model applying the concept of PDCA and as such counts on the consent of companies for implementing the model using human resources (internal technical team) from each company.

The following procedures are presented for the implementation of Company Participatory Ergonomics Management:

Step 1 - Training for the In-house Team (COERGO);

Step 2 - Mapping out the Production Line Work Stations;

Step 3 - Ergonomic Assessment (according to NR-17 regulations);

Step 4 - Introducing Ergonomic Action;

Step 5 - Assessing the Ergonomic Action with the Collaborators;

Step 6 - Implementation of Ergonomic Action;

Step 7 - Measuring and Assessment of results;

Step 8-Further Ergonomic Actions.

Using the above mentioned process, we carried out the two studies, taking into account their respective idiosyncrasies.

Case 1 - Assessment of the Ergonomic Quality of Working Conditions on the Production Line for ovens:

In order to assess the work station, the recommendations of the provisions contained in NR-17 were used, creating a criterion where it was possible to identify the status of each item from NR-17 on Ergonomics, in a simple and objective format, for the assessment of the work station.

The assessment of the work station is determined by a qualitative value (station grading) on the current state representing the level of conformity in that work station relative to the items contained in NR-17 Ergonomics regulations.

Therefore, each relevant item contained in NR-17 has a grade varying from 1 to 3, as follows: Grade 3 = in conformity (adequate); Grade 2 = partial conformity (partially adequate); Grade 1 = non conformity (inadequate). We would emphasize that the 5 items assessed are the minimum requirements under NR-17 on Ergonomics, which are:

1. Lifting, Transporting and Handling of Materials;

2. Work station furniture;

3. Work station equipment;

4. Environment Conditions;

5. Work Organization. 
The final grading of the station is determined by the sum of the 5 above mentioned items; the final grade representing the level of adequacy/inadequacy of the station or task relative to the needs of the worker and consequently, represents the level of conformity with NR-17 Ergonomic standards.

In calculating the result of the adequacy/inadequacy level for each item of NR-17, which represents the different impacts on the general state of the station and/or the adaptability of the station or task for the operator, the Weighted Average rate concept was used to determine the final grading for that station.

The weighting of the grades for each item in NR17 is made by taking into account the impact that each item has on the physical, psychological and cognizant well being of the operator performing his task at that station. For the weighting, specific weights were established for each of the items under consideration, in accordance with the following:

Weighting 2 for item 1 - Study of Transport and Handling of Materials;

Weighting 2 for item 2 - Work station furniture; Weighting 2 for item 3 - Work station equipment and accessories;

Weighting 1 for item 4 - Local Ambient Conditions; Weighting 3 for item 5 - Work Organization.

Using the abovementioned concepts and criteria, we arrive at the equation for determining the GRADE for the STATION (NP) as stated in equation 1:

\section{Eq. [1]}

$$
\mathbf{N P}=\frac{\sum(\mathrm{i} 1 \times 2)+(\mathrm{i} 2 \times 2)+(\mathrm{i} 3 \times 2)+(\mathrm{i} 4 \times 1)+(\mathrm{i} 5 \times 3)}{10}
$$

Therefore, the final grade (NP) represents the status of the ergonomic conditions found within that work station. At the same time this represents an indicator for the company when establishing a plan of action for implementing ergonomic improvements required by Ministry of Labor and Employment (MTE) NR-17 Ergonomic regulations.

The assessments of the work stations are made visually, through 2 qualitative graphs, the first re- cording the qualitative assessments of each individual item for the work station, where:

GRADE 1 (inadequate) represented by the red column;

GRADE 2 (partially adequate) represented by the yellow column;

GRADE 3 (adequate) represented by the green column.

The items 01 to 05 in Figure 1 represent the items from NR-17.

Figure 1

Classification of the items from NR-17

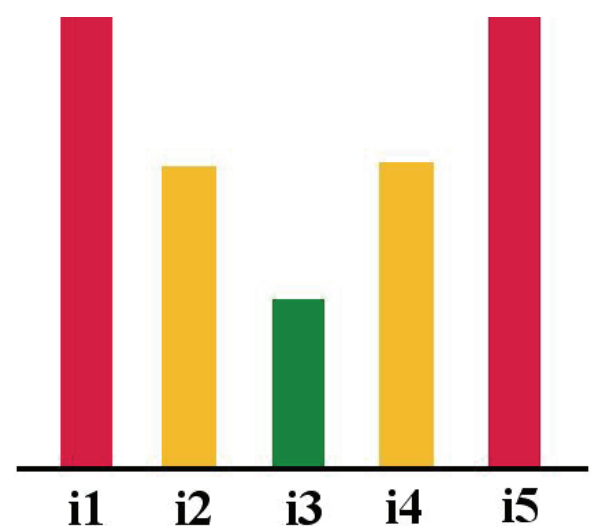

The above graph aims at identifying those items which are in a non-conformity (inadequate), partial conformity (partially adequate) and in a conformity (adequate) status. This allows us to identify the most critical or least critical item in order that the company can establish a timely action plan at that station, to make improvements and consequently improve the working conditions and the well being of the operator, contributing to his quality of life in the Work Station.

The second graph (Figure 2) demonstrates the qualitative assessment of the individual work stations, by applying the equation for STATION GRADE (NP), relative to the items mentioned in NR17 for each station.

FINAL GRADE (NP) from 1,0 to 1,5 (inadequate station) represented by the red column;

FINAL GRADE (NP) from 1,6 to 2,5 (partially adequate station) represented by the yellow column; 
FINAL GRADE (NP) from 2,6 to 3,0 (adequate station) represented by the green column.

The below graph (Figure 2) demonstrates a group of work stations from a production line, identifying the adequate stations (green); the partially adequate stations (yellow) and the inadequate stations (red).

This graph identifies the degree of severity in relation to non conformity with NR-17 Ergonomic regulations. This allows the company to establish a strategy for implementing a plan of action in order to improve work conditions at the work stations and those of the tasks which is the central objective of NR-17.

In this way we have created for ourselves a simple tool that is easy to apply for the Company Ergonomics Management, which is a continual improvement process for work conditions aimed at meeting current labor legislation and, therefore providing better working conditions for workers and a consequent improvement in quality and productivity from the operations at the various work stations and in how that reflects on an improvement in the service and product quality as well as quality of life for the workers.

By making a conformity assessment for meeting NR-17 requirements before and after implementation of ergonomic improvements, it was possible to iden- tify and measure the inadequacies of the relevant items in NR-17 by each work station before intervention as well as after intervention, demonstrating the effectiveness of the system. The graphs ( Figure 3, Figure 4 and Figure 5 ) demonstrate this.

Case 1 - Assessment of Ergonomic Quality on Work Conditions at a Metallic Packing Line:

By applying the same assessment model to the second case, similar results were encountered.

The graphs demonstrated a significant reduction at the various work stations, in the level of non conformity with NR-17 Ergonomic requirements, although the vast majority only achieved partial conformity and few work stations achieving total conformity, making it necessary for the continuation of the Ergonomic Participatory Management System as proposed by the researcher.

Figure 2

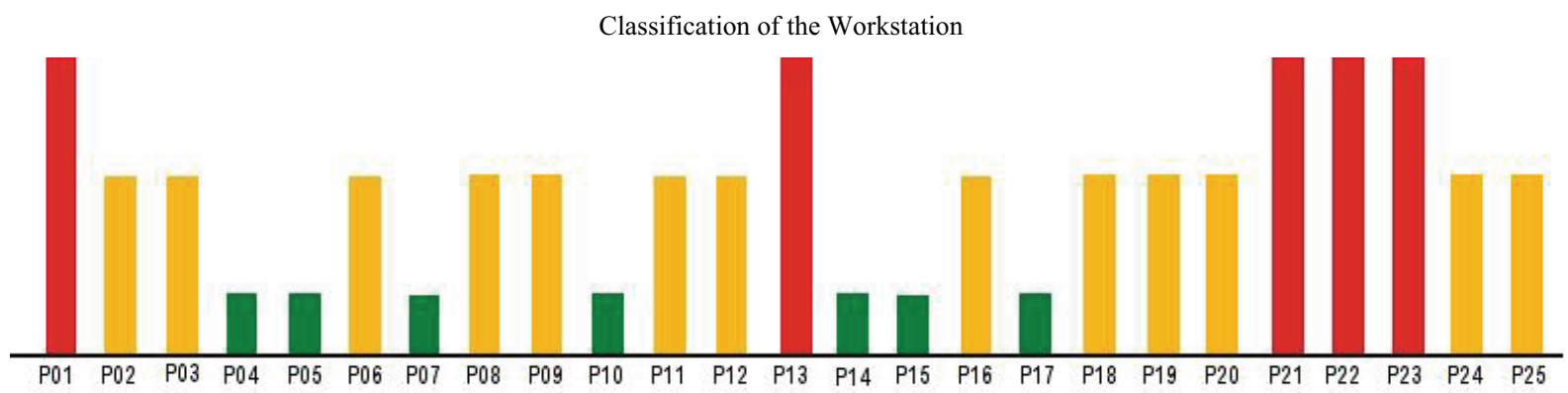


Figure 3

Graphs demonstrating the assessments by production line work stations before and after the implementation of ergonomic improvements.
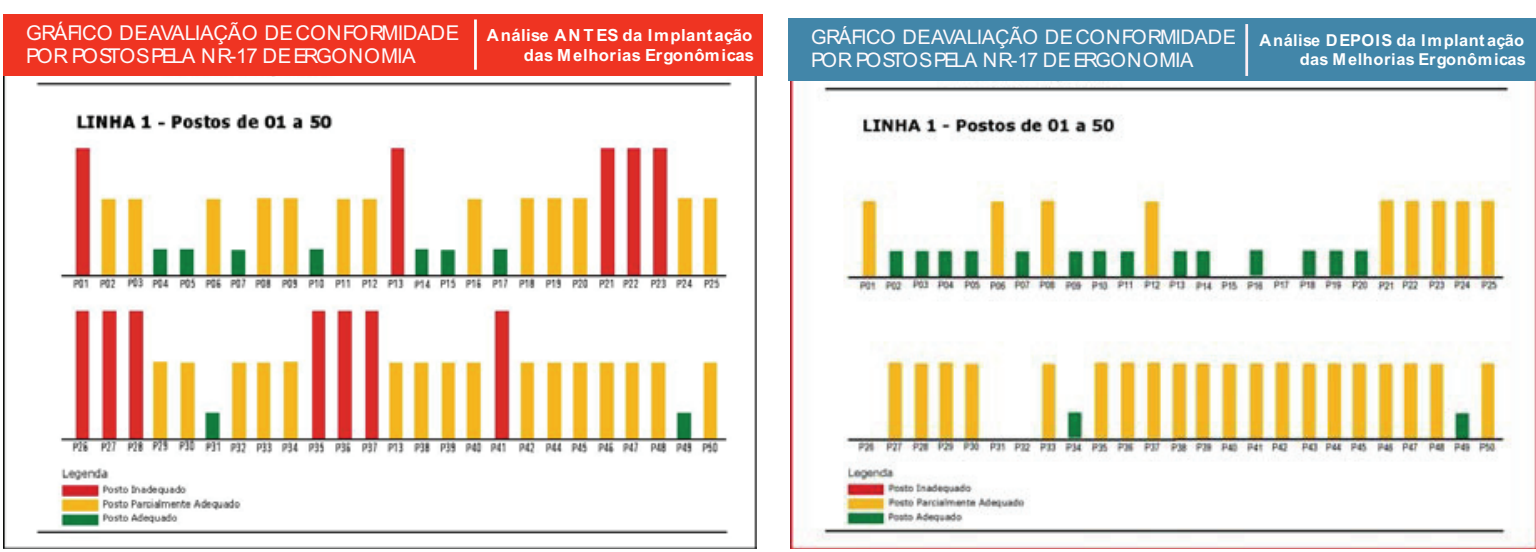

Figure 4

Graphs demonstrating the assessments of the various work stations for the items in NR-17 on Ergonomics before (left) and after (right) the implementation of ergonomic improvements.

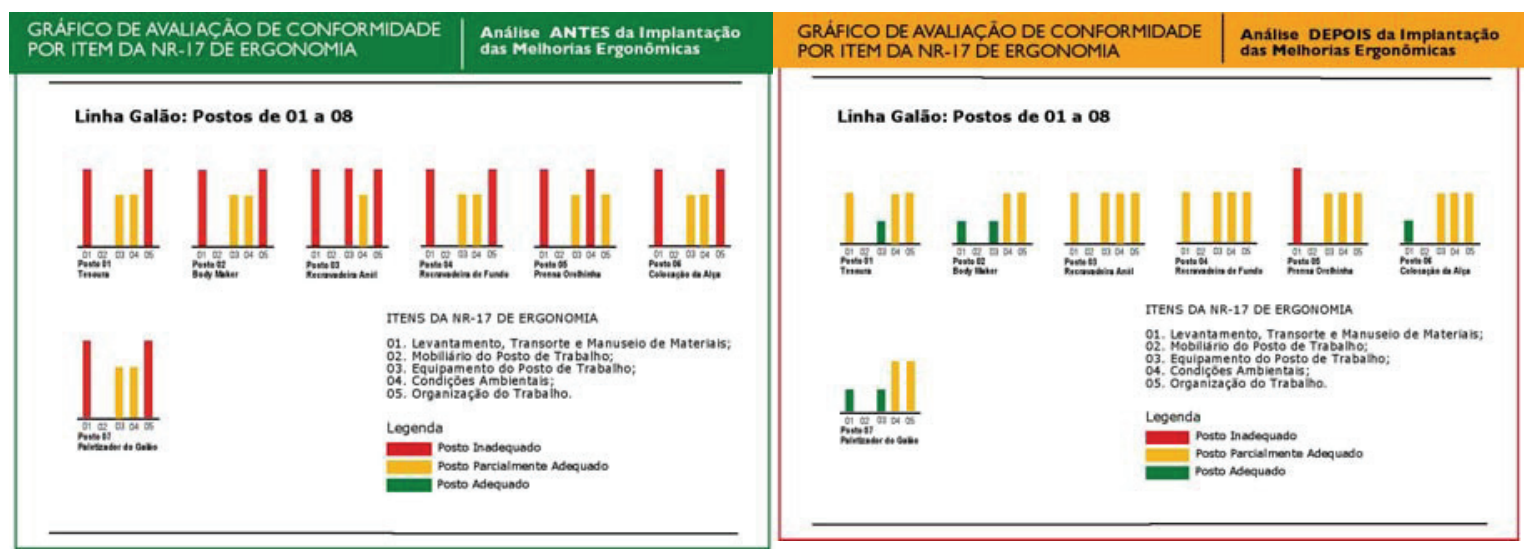

Figure 5

Graphs demonstrating the assessments by production line work stations before and after the implementation of ergonomic improvements.
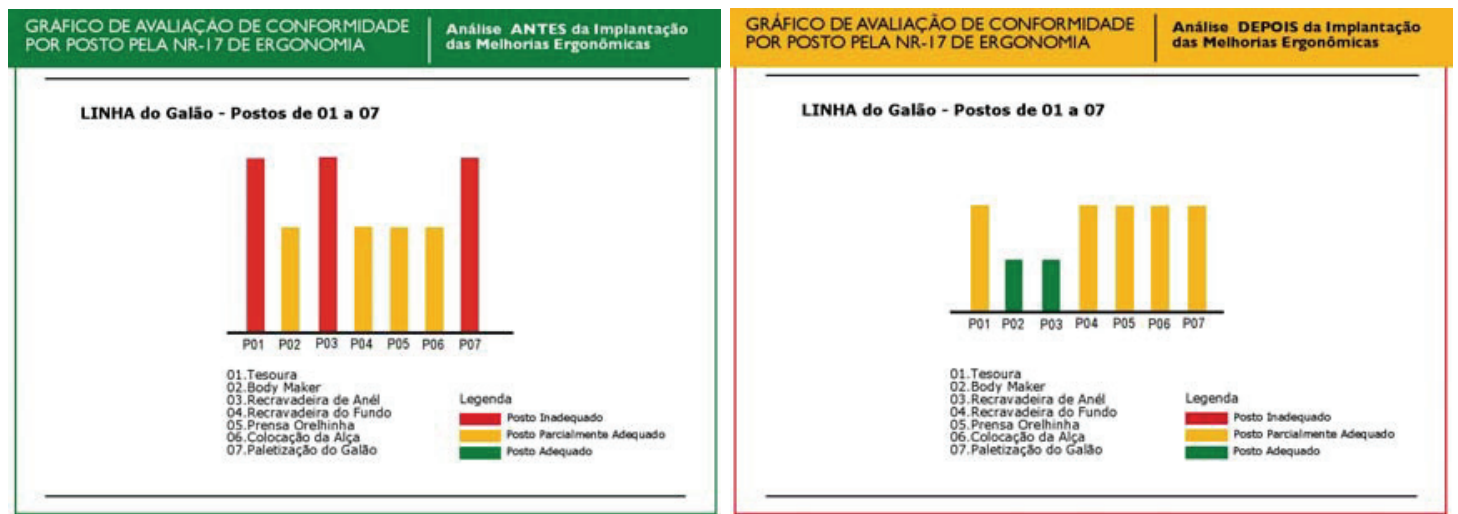


\section{Final Considerations}

The model demonstrated its effectiveness in the two case studies, because in both cases the identification of the non conformities was clear relative to the objective of indicating which items from NR-17 were in non conformity, with partial conformity or in conformity.

The contribution made by Ergonomics in its wide reaching scope is unquestionable and of unequaled importance for improving the workers quality of life and the quality and productivity within the companies, being of equal interest to workers, companies and our own Brazilian government, as this deals with a public policy carried out by private initiative which had big repercussions on workers health and consequently, benefits to the product and productivity quality also as well as a reduction in social costs to the country as a whole.

Following this study, it can be seen that the Ergonomics Management Model makes a contribution to the practical application of Ergonomics in companies relative to their various needs. The authors still emphasize that "Quality" is the result of various combined values relative to services and products which make them superior to or better than their competition and/or similar", and that, "Ergonomic Quality for working conditions must be supported by scien- tific holistic knowledge, without limitations or restrictions, and this knowledge should be used as an art, a technique, an ethic and above all, with human sensitivity for a better world, more just and supportive", ......because using the principles of Ergonomics is to do the very best for the individual, for the company and for society.

\section{References}

[1] C. Dejours, Epistemologia Concreta e Ergonomia. In: Daniellou, F. (Org.). A Ergonomia em Busca de seus Princípios: Debates Epistemológicos, São Paulo, Edgard Blucher (2004).

[2] D. Braatz, Validação: Uma Abordagem Conceitual Baseada na Dualidade da Ergonomia, in: Anais do Congresso Brasileiro de Ergonomia - 02 a 06 Agosto de 2010, ABERGO, Rio de Janeiro (2010).

[3] I. Iida, Ergonomia: Projeto e Produção - $2^{\circ}$ edição revista e ampliada, São Paulo, Edgard Blucher (2005).

[4] J. Abraão; L. Sznelwar; A. Silvanoi; M. Samet; D. Pinho, Introdução à Ergonomia: da Prática à Teoria. São Paulo: Edgard Blucher (2009).

[5] P. Falzon, Ergonomia, São Paulo, Edgard Blucher (2007).

[6] P. L. Costa Neto (coordenação), Qualidade e Competência nas Decisões, cap. 6 pp. 87, São Paulo, Editora Edgard Blucher (2007). 